\title{
Intravitreal bevacizumab (Avastin) therapy versus photodynamic therapy plus intravitreal triamcinolone for neovascular age-related macular degeneration: 6- month results of a prospective, randomised, controlled clinical study
}

\author{
G Weigert, ${ }^{1,2}$ S Michels, ${ }^{1,3}$ S Sacu, ${ }^{1}$ A Varga, ${ }^{1}$ F Prager, ${ }^{1}$ W Geitzenauer, ${ }^{1}$ U Schmidt- \\ Erfurth ${ }^{1}$
}

${ }^{1}$ Department of Ophthalmology, Medical University of Vienna, Vienna, Austria; ${ }^{2}$ Department of Clinical Pharmacology, Medical University of Vienna, Vienna, Austria: ${ }^{3}$ Department of Ophthalmology, University Hospital Zurich, Zurich,

Switzerland

Correspondence to: Dr S Michels, Department of Ophthalmology, University Hospital Zürich,

Frauenklinikstrasse 24, 8091 Zürich, Switzerland; stephan. michels@usz.ch

Accepted 11 September 2007

\section{ABSTRACT}

Aims: To compare functional and anatomical outcomes of intravitreal bevacizumab (Avastin) and verteporfin (photodynamic) therapy (PDT) combined with intravitreal triamcinolone (IVTA) in patients with neovascular agerelated macular degeneration (AMD).

Methods: Twenty-eight patients with neovascular AMD were enrolled in a prospective, randomised, controlled clinical trial. All patients randomly assigned to $1 \mathrm{mg}$ intravitreal bevacizumab $(0.04 \mathrm{ml})$ received three initial treatments at 4-week intervals. In further follow-up retreatment was based on optical coherence tomography (OCT). Patients randomly assigned to standard PDT received a same-day intravitreal injection of $4 \mathrm{mg}$ triamcinolone (Kenalog). Retreatment was based on fluorescein angiography at 3-month intervals. Functional and anatomical results were evaluated using the Early Treatment Diabetic Retinopathy Study protocol vision charts, fluorescein angiography and OCT.

Results: In the bevacizumab-treated group mean visual acuity (VA) improved to a 2.2 line gain at 6 months follow-up. Eyes treated in the PDT plus IVTA group had a stable mean VA at month 6 compared with baseline. There was a statistically significant difference $(p=0.03$, analysis of variance (ANOVA)) between both groups as early as one day after initial treatment. The reduction in central retinal thickness (CRT) showed no significant difference between both groups ( $p=0.3$, ANOVA). Mean CRT was reduced from $357 \mu \mathrm{m}$ at baseline to $239 \mu \mathrm{m}$ at month 6 in bevacizumab-treated patients and from $326 \mu \mathrm{m}$ to $222 \mu \mathrm{m}$, respectively, in PDT plus IVTAtreated patients. No significant local or systemic safety concerns were detected up to month 6 .

Conclusion: Intravitreal bevacizumab showed promising 6-month results in patients with neovascular AMD. Functional outcomes appear not only to be dependent on a reduction in CRT but also on the treatment modality used.

Anti-vascular endothelial growth factor (VEGF) therapy for age-related macular degeneration (AMD), one of the leading causes of severe vision loss in the developed world, ${ }^{1-3}$ has probably been the most promising breakthrough in medical retina treatment in recent years. For the first time in the treatment of neovascular AMD a therapeutic strategy binding all isoforms of VEGF has been able to show a real stabilisation of vision in phase
III clinical trials. ${ }^{45}$ An improvement in vision has even been reported in approximately $25 \%$ to $40 \%$ of patients at 1-year follow-up and appears to be maintained at 2 years. These results have, however, been obtained using monthly re-injections of ranibizumab independent of disease status. A recent prospective study on an optical coherence tomography (OCT)-based retreatment regimen for ranibizumab obtained similar results with regard to maintaining and improving vision. This treatment regimen also allowed a reduction in the number of treatments to 5.6 within the first year but did not reduce the number of patient visits. ${ }^{6}$

Bevacizumab, a full-length monoclonal antibody binding all isoforms of VEGF, has been primarily developed for systemic therapy in cancer patients. The first reports on "off-label" bevacizumab in ophthalmology showed the systemic use of the drug to be effective in patients with neovascular AMD. ${ }^{78}$ The real breakthrough for the use of bevacizumab came with first reports on the effectiveness of "off-label" intravitreal bevacizumab for neovascular AMD and retinal vein occlusions, ${ }^{9}{ }^{10}$ as well as studies documenting the retinal penetration of the relatively large $(\sim 150 \mathrm{kDa})$ monoclonal antibody. ${ }^{11}$ In the meantime, several retrospective and prospective studies have indicated beneficial effects and a good safety profile of intravitreal bevacizumab for neovascular $\mathrm{AMD}$, but phase III studies are currently missing. ${ }^{12-20} \mathrm{~A}$ major disadvantage of the inexpensive "off-label" drug appears to be, similar to other intravitreally given anti-VEGF drugs, the frequent requirement for retreatment.

The combination of verteporfin (photodynamic) therapy (PDT) with intravitreal triamcinolone (IVTA) has been the standard of care for many patients with neovascular AMD. Major advantages of this combination strategy appeared to be better functional results compared with PDT or IVTA monotherapy and an extended treatment durability requiring retreatment as infrequently as less than two treatments per year. ${ }^{21-24}$ The major disadvantages were steroid-induced adverse effects such as ocular hypertension/glaucoma and the progression of cataracts. ${ }^{25} 26$

The present study compares functional and anatomical outcomes of $1 \mathrm{mg}(0.04 \mathrm{ml})$ intravitreal bevacizumab with PDT plus $4 \mathrm{mg}$ IVTA $(0.1 \mathrm{ml})$. 
Table 1 Baseline characteristics

\begin{tabular}{|c|c|c|c|c|}
\hline & $\mathbf{N}$ & $\begin{array}{l}\text { Visual acuity } \\
\text { (ETDRS } 2 \mathrm{~m} \text { ) }\end{array}$ & $\begin{array}{l}\text { Central } 1 \mathrm{~mm} \text { retinal } \\
\text { thickness }\end{array}$ & Angiographic lesion type \\
\hline Bevacizumab & 14 & 50 letters & $357 \mu \mathrm{m}$ & $\begin{array}{l}\text { Predominantly classic } 5 \\
\text { Minimally classic } 2 \\
\text { Occult only } 7\end{array}$ \\
\hline PDT + IVTA & 14 & 46 letters & $326 \mu \mathrm{m}$ & $\begin{array}{l}\text { Predominantly classic } 2 \\
\text { Minimally classic } 5 \\
\text { Occult only } 7\end{array}$ \\
\hline
\end{tabular}

ETDRS, Early Treatment Diabetic Retinopathy Study protocol vision chart; IVTA, intravitreal triamcinolone; PDT, verteporfin therapy.

\section{PATIENTS AND METHODS}

The study protocol was approved by the Ethics Committee of the Medical University of Vienna, the Austrian health authorities, was registered at the European Clinical Trials Database (EudraCT no 2005-003288-21) and adhered to the guidelines of the declaration of Helsinki. All patients signed written informed consent before enrollment into the study.

The study was designed as an open-label, single-centre, randomised, controlled clinical trial. Primary and secondary outcomes were a change in mean visual acuity (VA) and mean $1 \mathrm{~mm}$ central retinal thickness comparing both treatment groups.

Enrolled patients had neovascular AMD of any lesion type smaller than four disc areas, without any previous treatment for neovascular AMD, and a VA of 20/40 to 20/800. Patients with a history of thromboembolic events within the past 3 months and a predictable need for ocular surgery were excluded from the study. Patients were randomly assigned $1: 1$ to $1 \mathrm{mg}$ intravitreal bevacizumab or standard PDT $\left(6 \mathrm{mg} / \mathrm{m}^{2}, 50 \mathrm{~J} / \mathrm{cm}^{2}\right.$, $600 \mathrm{~mW} / \mathrm{cm}^{2}$, 83 seconds light application) plus $4 \mathrm{mg}$ IVTA.

All patients were evaluated at baseline, day 1, day 7, months 1, 3 and 6 by VA testing using Early Treatment Diabetic Retinopathy Study (ETDRS) charts at two meters, OCT and complete ophthalmic examination. Fluorescein angiography and indocyanine green angiography as well as microperimetry were performed at baseline, months 3 and 6 . Patients randomly assigned to intravitreal bevacizumab were also seen at months 2,4 and 5 .

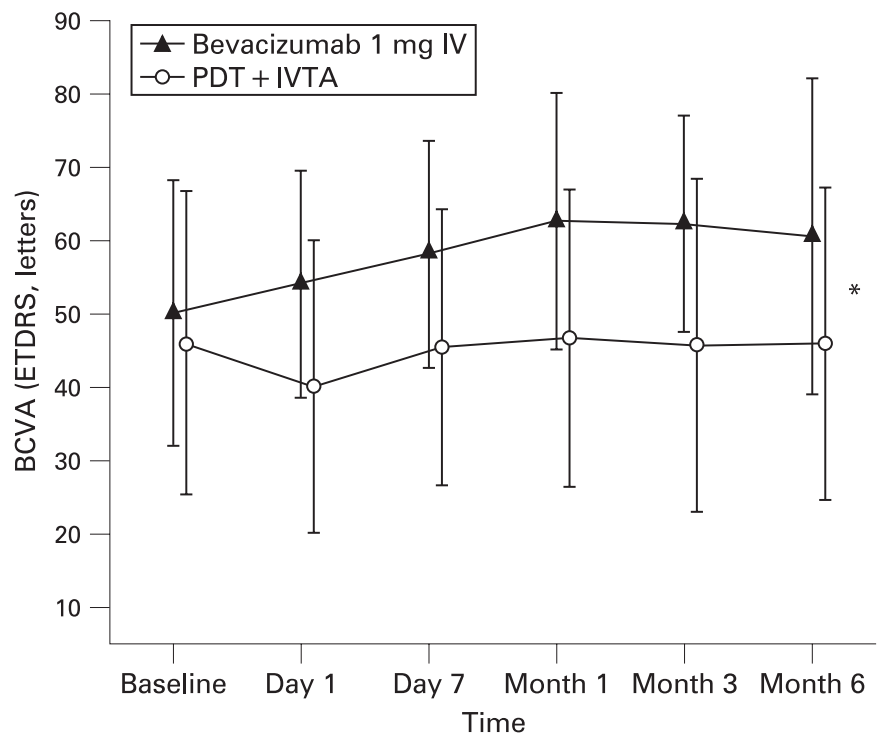

Figure 1 The course of best-corrected visual acuity (BCVA) at 6-months follow-up comparing $1 \mathrm{mg}$ intravitreal (IV) bevacizumab with verteporfin therapy (PDT) plus $4 \mathrm{mg}$ intravitreal triamcinolone (IVTA). ETDRS, Early Treatment Diabetic Retinopathy Study protocol vision chart. Data are presented as means \pm SD. ${ }^{*} p<0.05$ between groups.
Three initial injections of $1 \mathrm{mg}(0.04 \mathrm{ml})$ bevacizumab were given at monthly intervals up to month 2 , thereafter retreatment was based on findings of OCT only. Indication for retreatment after the third injection was evidence of persistent or recurrent intra or subretinal fluid by OCT. A stable pigment epithelial detachment without these findings was no indication for retreatment. Patients in the PDT plus IVTA group were retreated at 3-month intervals if there was evidence of leakage by fluorescein angiography.

Intravitreal injections of bevacizumab (Avastin; Roche Basel, $\mathrm{CH}$; Genentech, Inc, South San Francisco, California, USA) and triamcinolone acetonide (Volon A; Bristol-Myers Squibb, New York, USA) were both performed in the operating room under sterile conditions following the guidelines of the Austrian ophthalmological society. For patients with previous PDT operating room lights were dimmed to avoid further photoactivation of verteporfin.

Bevacizumab was prepared by the institutional pharmacy as sterile filled and packed tuberculin syringes containing $0.2 \mathrm{ml}$; $0.04 \mathrm{ml}(1 \mathrm{mg})$ bevacizumab was injected intravitreally using a 30 gauge needle. Triamcinolone acetonide was washed and prepared according to previous publications. ${ }^{27} \mathrm{~A} 27$ gauge needle was used to inject $4 \mathrm{mg}$ triamcinolone $(0.1 \mathrm{ml})$ intravitreally.

For statistical analysis analysis of variance (ANOVA) was used to compare mean VA and mean CRT of both treatment arms. For comparison of VA and CRT outcomes within each

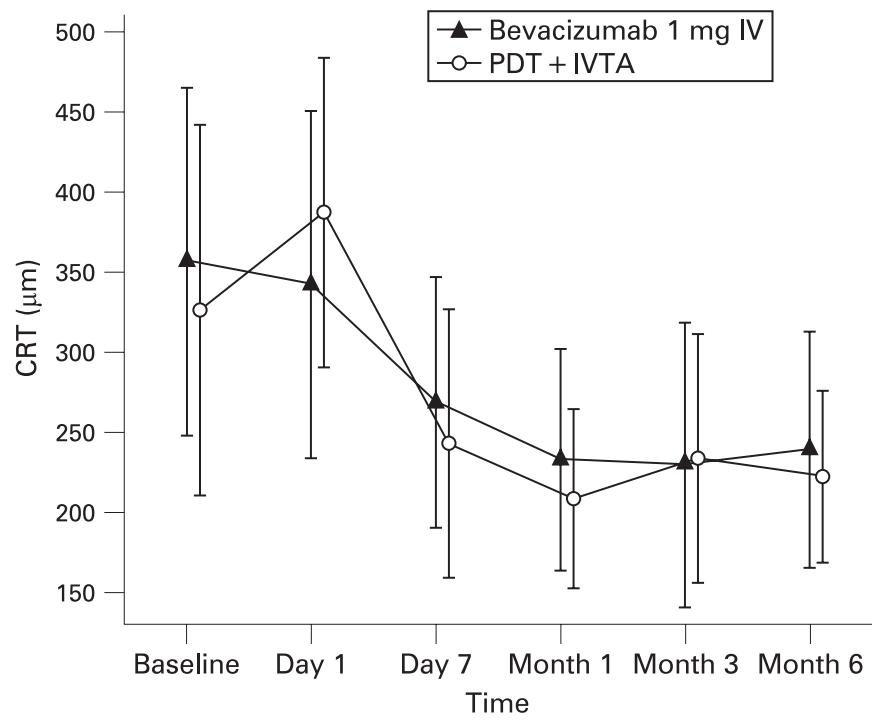

Figure 2 The course of central retinal thickness (CRT) at 6-months follow-up comparing $1 \mathrm{mg}$ intravitreal (IV) bevacizumab with verteporfin therapy (PDT) plus $4 \mathrm{mg}$ intravitreal triamcinolone (IVTA).

Data are presented as means \pm SD. 


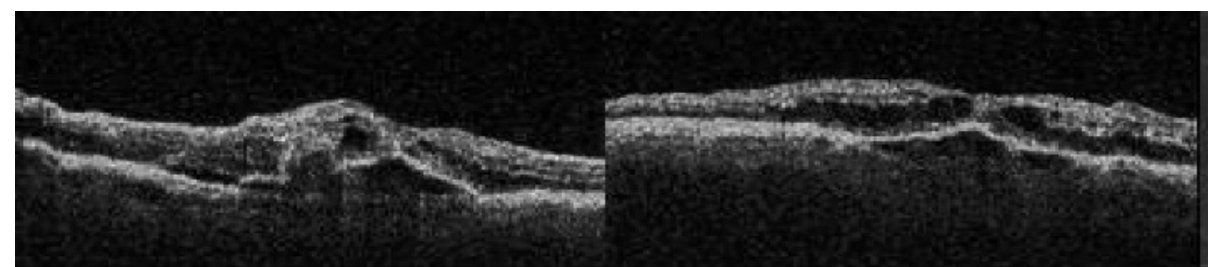

Baseline: 57 letters; CRT: $355 \mu \mathrm{m}$
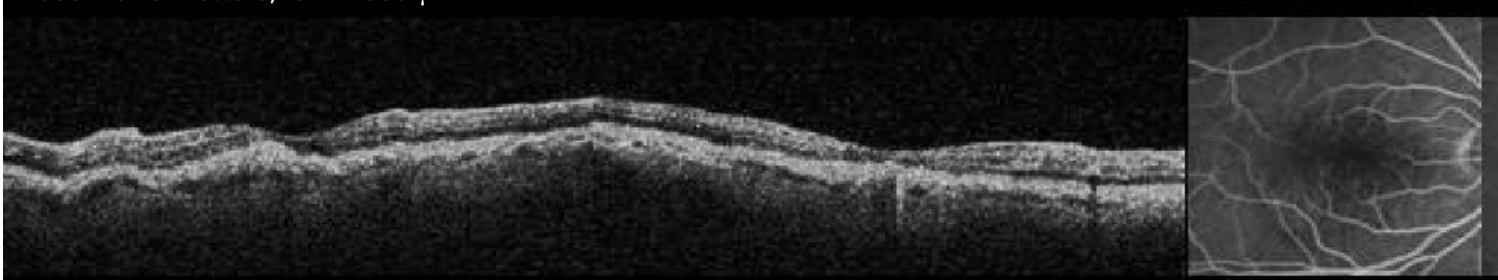

Month 1: 63 letters (+6); CRT: $210 \mu \mathrm{m}$

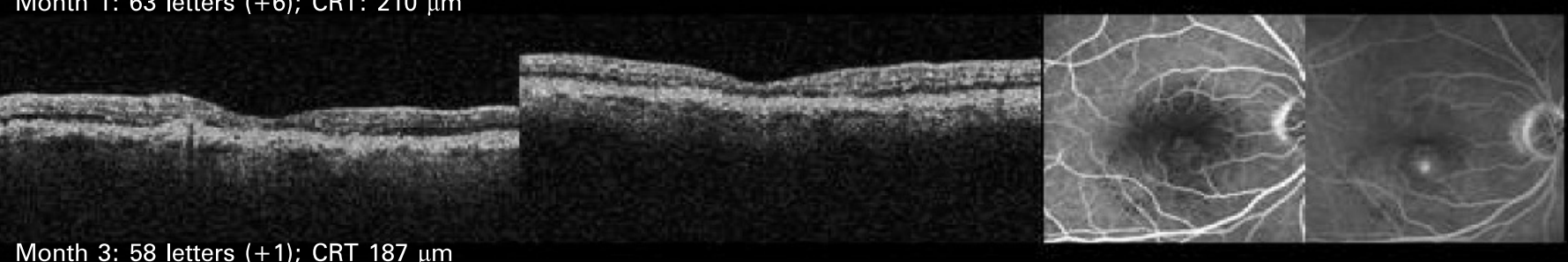

Month 3: 58 letters (+1); CRT $187 \mu \mathrm{m}$

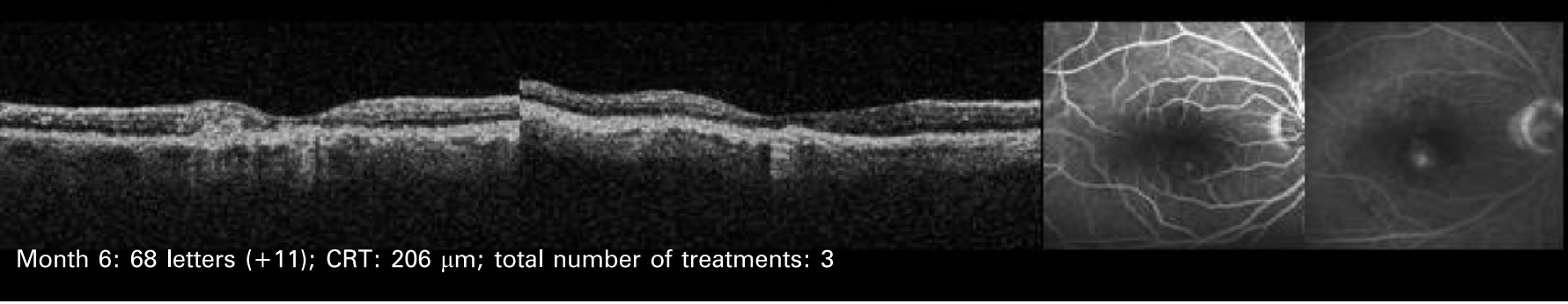

Figure 3 Retinal angiomatous proliferation treated with $1 \mathrm{mg}$ intravitreal bevacizumab. CRT, central retinal thickness.

group with baseline the t-test was used. P values of less than 0.05 were considered statistically significant.

\section{RESULTS}

Twenty-eight patients, 19 women and nine men, were enrolled into the study, 14 into each arm. The mean age was 78 (SD 8) years (range 58 to 88 years). Baseline characteristics were well balanced (table 1). There was no statistically significant difference with regard to VA and CRT at baseline.

Up to month 6 no patient was excluded from the study and month 6 follow-up was $100 \%$ in the bevacizumab-treated group and one patient failed to follow up at month 6 in the PDT plus IVTA-treated group.

Mean VA of eyes enrolled into the bevacizumab treatment arm improved from 50 letters $(20 / 100)$ at baseline to 54 letters $\left(20 / 80^{-1}\right)$ at day 1,58 letters $\left(20 / 63^{-2}\right)$ at week 1,62 letters $(20 /$ $\left.63^{+2}\right)$ at month 3 and 61 letters $\left(20 / 63^{+1}\right)$ at month 6 (fig 1). Compared with baseline changes in VA were statistically significant ( $p=0.005$, t-test) as early as week 1 .

Mean VA of eyes enrolled into the PDT plus IVTA group showed a moderate decrease from 46 letters $\left(20 / 125^{+1}\right)$ at baseline to 40 letters $(20 / 160)$ at day 1 and then returned to 46 letters $\left(20 / 125^{+1}\right)$ at week 1 , stayed at 46 letters $\left(20 / 125^{+1}\right)$ at month 3 and 46 letters $\left(20 / 125^{+1}\right)$ at month 6 (fig 1).

Comparing the mean VA of both groups, the primary endpoint for the study, showed a statistically significant difference between both groups in favour of the bevacizumabtreated group as early as day $1(p=0.03$, ANOVA between groups). Table 2 outlines the distribution of change in VA for both groups.

Table 2 Frequency distribution of changes in best-corrected visual acuity from baseline to month 6

\begin{tabular}{|c|c|c|}
\hline \multirow[b]{2}{*}{ Change in BCVA } & \multicolumn{2}{|l|}{ Eyes, n (\%) } \\
\hline & $\begin{array}{l}\text { Bevacizumab } \\
(\mathrm{n}=14)\end{array}$ & $\begin{array}{l}\text { PDT plus IVTA } \\
(\mathrm{n}=14)\end{array}$ \\
\hline$\geqslant 3$-Line increase & $5(36)$ & $3(21)$ \\
\hline 0 to $<3$-Line increase & $7(50)$ & $4(29)$ \\
\hline$<3$-Line decrease & $2(14)$ & $5(36)$ \\
\hline$\geqslant 3$-Line decrease & $0(0)$ & $2(14)$ \\
\hline
\end{tabular}

BCVA, Best-corrected visual acuity; IVTA, intravitreal triamcinolone; PDT, verteporfin therapy. 


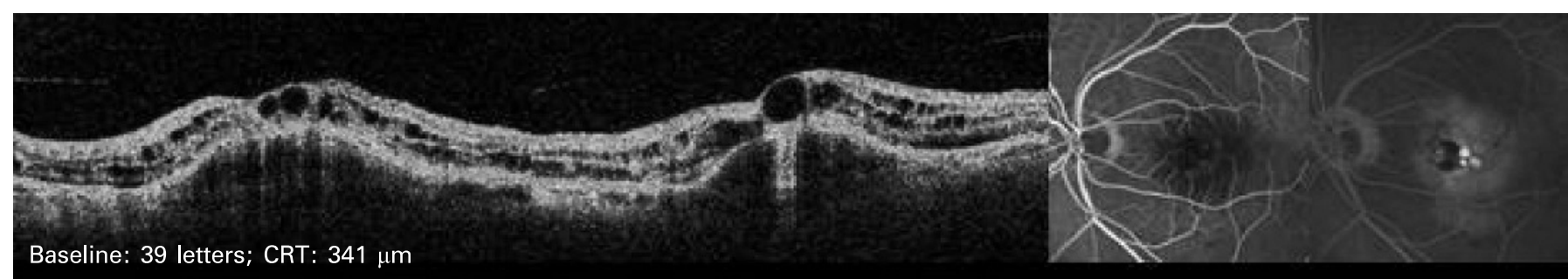

Baseline: 39 letters; CRT: $341 \mu \mathrm{m}$

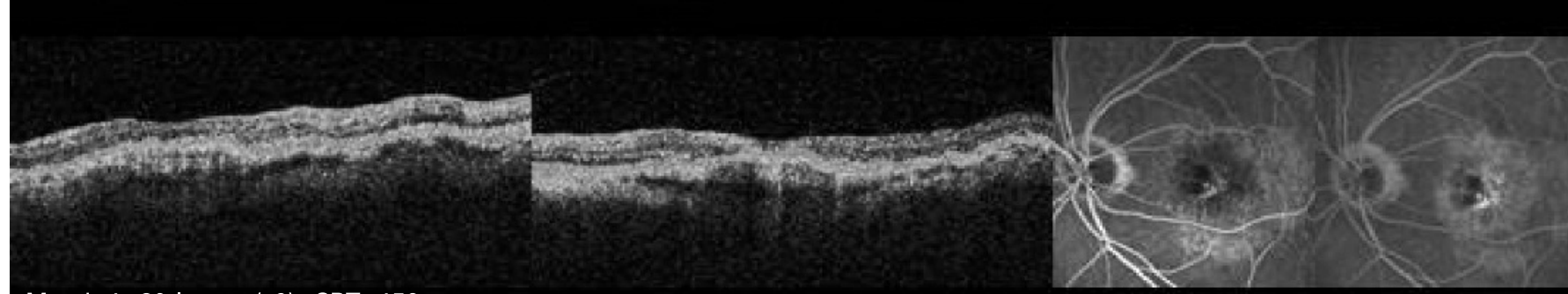

Month 1: 30 letters (-9); CRT: $156 \mu \mathrm{m}$

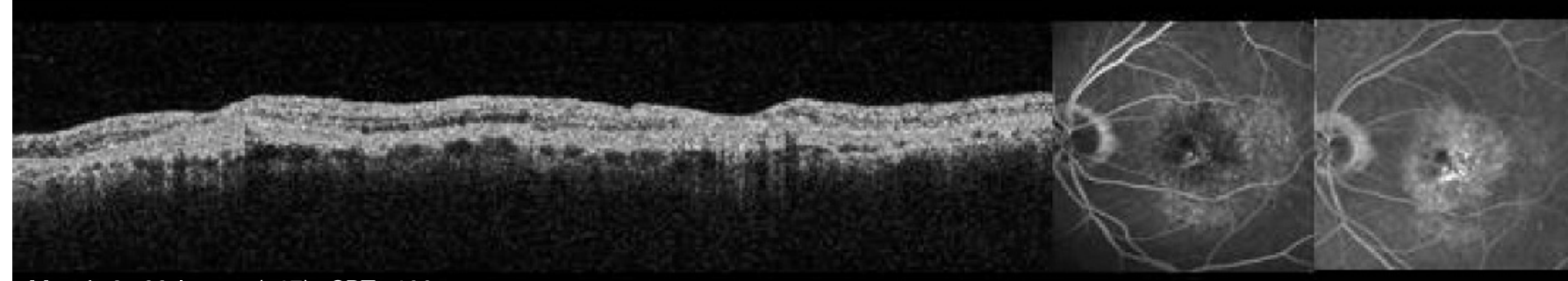

Month 3: 22 letters (-17); CRT: $190 \mu \mathrm{m}$

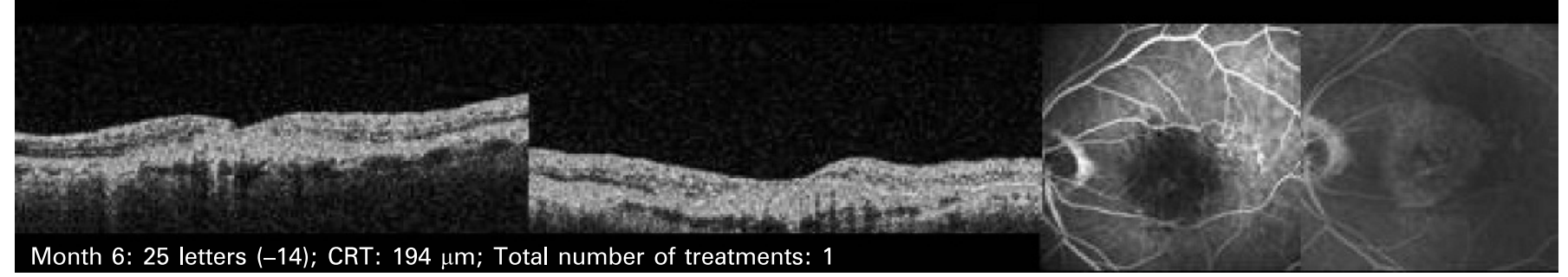

Figure 4 Angiomatous proliferation treated with photodynamic therapy (PDT) plus $4 \mathrm{mg}$ intravitreal triamcinolone. CRT, central retinal thickness.

Mean CRT showed similar changes for both groups up to month 6 follow-up. It decreased in the bevacizumab-treated group from $357 \mu \mathrm{m}$ at baseline to $342 \mu \mathrm{m}$ at day 1, $268 \mu \mathrm{m}$ at week 1, $230 \mu \mathrm{m}$ at month 3 and $239 \mu \mathrm{m}$ at month 6 (fig 2). Compared with baseline the decrease in mean CRT became statistically significant as early as week $1(p<0.005)$. In the PDT plus IVTA group mean CRT decreased from $326 \mu \mathrm{m}$ at baseline, except for an increase to $387 \mu \mathrm{m}$ at day 1 , continuously to $243 \mu \mathrm{m}$ at week $1,234 \mu \mathrm{m}$ at month 3 and $222 \mu \mathrm{m}$ at month 6 (fig 2). Compared with baseline the decrease in CRT became statistically significant as early as week $1(p=0.002)$. There was no statistically significant difference between both groups with regard to CRT ( $p=0.3$, ANOVA between groups), the secondary endpoint of the study, even not on day $1(p=0.2$, t-test). Figures 3 and 4 show examples of eyes treated in both treatment arms.

The mean number of treatments including month 6 was 4.5 out of seven possible treatments in the bevacizumab-treated group and 1.9 out of three possible treatments in the PDT plus IVTA-treated group. At months 3 and $650 \% / 43 \%$ required retreatment in the bevacizumab group and $79 \% / 14 \%$, respectively, in the PDT plus IVTA group.

The correlation coefficient ( $r$ ) was used for the calculation of the correlation between the change in VA and a change in CRT.
A significant correlation was found for the bevacizumab-treated group at month $1(\mathrm{r}=-0.55 ; \mathrm{p}=0.04)$ but not for the PDT plus IVTA-treated group $(r=-0.19 ; p=0.5)$. At months 3 and 6 the correlations did not quite reach significance in the bevacizumabtreated group $(r=-0.5 ; p=0.066$ and $r=-0.47 ; p=0.089$, respectively) and were again not significant for the PDT plus IVTA-treated group $(r=-0.24 ; p=0.4$ and $r=-0.10 ; p=0.7$, respectively).

In none of the groups was a severe ocular (eg traumatic cataract, retinal detachment, endopthalmitis, severe ocular inflammation) or systemic adverse event reported up to month 6. Two patients in the PDT plus IVTA group experienced slightly elevated intraocular pressure (IOP) values (25 and $26 \mathrm{~mm} \mathrm{Hg}$ ) during one week after initial treatment and received topical IOP-lowering medication. For none of the bevacizumab-treated patients was an elevated IOP detected. In neither group was significant cataract progression noted within 6 months follow-up. Indocyanine green angiography showed no evidence of significant bevacizumab-associated choroidal perfusion changes. Patients in the PDT plus IVTA group had characteristic hypofluorescence within the area of the PDT treatment spot, but there was no evidence of treatmentassociated choroidal hypoperfusion outside the area of the PDT treatment spot. 


\section{DISCUSSION}

The results of this prospective, randomised, controlled clinical study have shown several clinically relevant findings. The use of $1 \mathrm{mg}$ intravitreal bevacizumab appears to have significantly better visual outcomes than the combination therapy of PDT plus $4 \mathrm{mg}$ IVTA in a selected patient population with neovascular AMD up to 6 months. Patients receiving bevacizumab gained a mean of more than two lines compared with a stable visual outcome in patients treated with PDT plus IVTA. The promising functional and anatomical results go along with results from uncontrolled studies. ${ }^{13-20}$ No severe ocular or systemic adverse events were found in both study groups up to 6 months. The study was, however, too small to provide profound safety data.

The results further indicate that an intermittent treatment regimen using OCT findings as an indicator for retreatment is most promising for managing AMD patients with intravitreal bevacizumab. Similar results have been published for the use of ranibizumab in neovascular AMD. ${ }^{6}$ Despite the risk of $\mathrm{CNV}$ recurrence and no fixed retreatment at month 5 the study protocol allowed for a significant improvement of vision. The major limitation of this study protocol, especially when compared with the retreatment regimen used for PDT plus IVTA, is that despite reducing the number of injections, the number of patient visits is not reduced.

A correlation of changes in CRT and VA has been found for systemic bevacizumab in neovascular AMD. ${ }^{7}$ This seems to be valid also for intravitreal bevacizumab at month 1 as shown in this study. This correlation appears to be dependent on the treatment modality used. The PDT plus IVTA-treated patients showed, except for a PDT-induced increase in CRT at day 1, a very similar time course and degree of reduction in CRT compared with bevacizumab-treated patients. However, VA results did not correlate with the CRT reduction. One can only speculate on the reasons for this finding. It is well known that standard PDT induces a transient reduction in the outer blood retinal barrier function early after treatment, ${ }^{28}{ }^{29}$ which seems not to be completely inhibited by same-day $4 \mathrm{mg}$ IVTA. PDT furthermore leads to an at least transient closure of the choriocapillaris, ${ }^{28}$ and an atrophy of the retinal pigment epithelium (RPE) after repeated treatments. ${ }^{30}$ Modified PDT treatment parameters might (eg reduced fluence) have less effect on choroid and RPE and might subsequently provide better outcomes. ${ }^{31}$ Triamcinolone, even after washing out preservatives, has also shown a toxic effect on RPE cells in cell culture models. ${ }^{32}$ Which treatment component is responsible for the worse functional outcomes in the PDT plus IVTA group remains to be determined. These findings might, however, make us further aware of the potential limitations of combination strategies with anti-angiogenic drugs, not with regard to treatment durability, but with regard to functional outcomes.

Despite the prospective, randomised, controlled study design, the study has clear limitations. The study was small, selected patients with relatively small, active CNV without any previous treatment and is so far limited to 6 months follow-up.

The trend indicated by the results of this study emphasises the potential value of intravitreal bevacizumab in neovascular $\mathrm{AMD}$ and supports the need for further large controlled clinical trials.

Competing interests: US-E is an owner of the patent on the use of green porphyrins in neovasculature of the eye under the guidelines of the Wellman Laboratories of Photomedicine, Harvard Medical School, Boston, Massachusetts, USA.

\section{REFERENCES}

1. Friedman DS, O'Colmain BJ, Munoz B, et al. Prevalence of age-related macular degeneration in the United States. Arch Ophthalmol 2004;122:564-72.
2. Congdon N, O'Colmain B, Klaver CC, et al. Causes and prevalence of visual impairment among adults in the United States. Arch Ophthalmol 2004;122:477-85.

3. Klaver CC, Wolfs RC, Vingerling JR, et al. Age-specific prevalence and causes of blindness and visual impairment in an older population: the Rotterdam Study. Arch Ophthalmol 1998;116:653-8.

4. Brown DM, Kaiser PK, Michels M, et al. Ranibizumab versus verteporfin for neovascular age-related macular degeneration. N Engl J Med 2006;355:1432-44.

5. Rosenfeld PJ, Brown DM, Heier JS, et al. Ranibizumab for neovascular age-related macular degeneration. N Engl J Med 2006;355:1419-31.

6. Fung $\mathbf{A E}$, Lalwani GA, Rosenfeld PJ, et al. An optical coherence tomography-guided variable dosing regimen with intravitreal ranibizumab (Lucentis) for neovascular agerelated macular degeneration. Am J Ophthalmol 2007;143:566-83.

7. Michels S, Rosenfeld PJ, Puliafito CA, et al. Systemic bevacizumab (Avastin) therapy for neovascular age-related macular degeneration: twelve-week results of an uncontrolled open-label clinical study. Ophthalmology 2005:112:1035-47.

8. Moshfeghi AA, Rosenfeld PJ, Puliafito CA, et al. Systemic bevacizumab (Avastin) therapy for neovascular age-related macular degeneration: twenty-four-week results of an uncontrolled open-label clinical study. Ophthalmology 2006;113:2002-16.

9. Rosenfeld PJ, Fung AE, Puliafito CA. Optical coherence tomography findings after an intravitreal injection of bevacizumab (avastin) for macular edema from central retinal vein occlusion. Ophthalmic Surg Lasers Imaging 2005;36:336-9.

10. Rosenfeld PJ, Moshfeghi AA, Puliafito CA. Optical coherence tomography findings after an intravitreal injection of bevacizumab (avastin) for neovascular age-related macular degeneration. Ophthalmic Surg Lasers Imaging 2005;36:331-5.

11. Shahar J, Avery RL, Heilweil G, et al. Electrophysiologic and retinal penetration studies following intravitreal injection of bevacizumab (Avastin). Retina 2006:26:262-9.

12. Abraham-Marin ML, Cortes-Luna CF, Alvarez-Rivera G, et al. Intravitreal bevacizumab therapy for neovascular age-related macular degeneration: a pilot study. Graefes Arch Clin Exp Ophthalmol 2007;245:651-5

13. Aggio FB, Farah ME, Silva WC, et al. Intravitreal bevacizumab for exudative agerelated macular degeneration after multiple treatments. Graefes Arch Clin Exp Ophthalmol 2007:245:215-220. Published Online First 1 December 2006. doi: 101007/s00417-006-0412-5.

14. Aisenbrey S, Ziemssen F, Volker M, et al. Intravitreal bevacizumab (Avastin) for occult choroidal neovascularization in age-related macular degeneration. Graefes Arch Clin Exp Ophthalmol 2007;245:941-8.

15. Avery RL, Pieramici DJ, Rabena MD, et al. Intravitreal bevacizumab (Avastin) for neovascular age-related macular degeneration. Ophthalmology 2006;113:363-72 e5.

16. Bashshur ZF, Bazarbachi A, Schakal A, et al. Intravitreal bevacizumab for the management of choroidal neovascularization in age-related macular degeneration. Am J Ophthalmol 2006;142:1-9.

17. Costa RA, Jorge R, Calucci D, et al. Intravitreal bevacizumab for choroidal neovascularization caused by AMD (IBeNA Study): results of a phase 1 doseescalation study. Invest Ophthalmol Vis Sci 2006;47:4569-78.

18. Lazic R, Gabric N. Intravitreally administered bevacizumab (Avastin) in minimally classic and occult choroidal neovascularization secondary to age-related macular degeneration. Graefes Arch Clin Exp Ophthalmol 2007;245:68-73.

19. Yoganathan P, Deramo VA, Lai JC, et al. Visual improvement following intravitreal bevacizumab (Avastin) in exudative age-related macular degeneration. Retina 2006;26:994-8.

20. Rich RM, Rosenfeld PJ, Puliafito CA, et al. Short-term safety and efficacy of intravitreal bevacizumab (Avastin) for neovascular age-related macular degeneration. Retina 2006:26:495-511.

21. Augustin AJ, Schmidt-Erfurth U. Verteporfin and intravitreal triamcinolone acetonide combination therapy for occult choroidal neovascularization in age-related macular degeneration. Am J Ophthalmol 2006;141:638-45.

22. Augustin AJ, Schmidt-Erfurth U. Verteporfin therapy combined with intravitreal triamcinolone in all types of choroidal neovascularization due to age-related macular degeneration. Ophthalmology 2006:113:14-22.

23. Spaide RF, Sorenson J, Maranan L. Combined photodynamic therapy and intravitreal triamcinolone for nonsubfoveal choroidal neovascularization. Retina 2005:25:685-90.

24. Spaide RF, Sorenson J, Maranan L. Photodynamic therapy with verteporfin combined with intravitreal injection of triamcinolone acetonide for choroidal neovascularization. Ophthalmology 2005;112:301-4.

25. Jonas JB, Degenring R, Vossmerbauemer $U$, et al. Frequency of cataract surgery after intravitreal injection of high-dosage triamcinolone acetonide. Eur J Ophthalmol 2005:15:462-4.

26. Rhee DJ, Peck RE, Belmont J, et al. Intraocular pressure alterations following intravitreal triamcinolone acetonide. Br J Ophthalmol 2006;90:999-1003.

27. Jonas JB, Kreissig I, Hugger $\mathrm{P}$, et al. Intravitreal triamcinolone acetonide for exudative age related macular degeneration. Br J Ophthalmol 2003;87:462-8.

28. Michels S, Schmidt-Erfurth U. Sequence of early vascular events after photodynamic therapy. Invest Ophthalmol Vis Sci 2003:44:2147-54.

29. Rogers $\mathbf{A H}$, Martidis A, Greenberg PB, et al. Optical coherence tomography findings following photodynamic therapy of choroidal neovascularization. Am J Ophthalmol 2002;134:566-76.

30. Schmidt-Erfurth UM, Michels S. Changes in confocal indocyanine green angiography through two years after photodynamic therapy with verteporfin. Ophthalmology 2003;110:1306-14.

31. Michels S, Hansmann F, Geitzenauer W, et al. Influence of treatment parameters on selectivity of verteporfin therapy. Invest Ophthalmol Vis Sci 2006;47:371-6.

32. Narayanan R, Mungcal JK, Kenney MC, et al. Toxicity of triamcinolone acetonide on retinal neurosensory and pigment epithelial cells. Invest Ophthalmol Vis Sci 2006:47:722-8. 